\title{
JOURNAL OF AVIATION
}

\section{Hava Araçlarında Kullanılan ULB Cihazlarının Güvenilirlik İncelemesi}

\section{Ercan KIVANÇ ${ }^{*}$, Satılmış $\ddot{U} R G \ddot{U} N^{2}$}

\author{
${ }^{1}$ Uçak Teknisyeni(Hat Bakım, Mekanik/Aviyonik), Pegasus Airlines, 34912, İstanbul
}

${ }^{2}$ Havacılık ve Uzay Bilimleri Fakültesi, Uçak Elektrik- Elektronik, Kocaeli Üniversitesi, 41285, Kocaeli.

\section{Özet}

Halk tarafindan genelde kara kutu olarak bilinen FDR(Flight Data Recorder) ve CVR(Cockpit Voice Recorder) kayit cihazları havacılık için çok önemlidir. Havacılıkta FDR ve CVR cihazlarına takılı olarak kullanılan ULB(Underwater Locator Beacon) ise su ile temas ettiğinde belirli bir frekansta akustik sinyal yayan bir sualtı ses vericisidir. Enkazın suya battığı hava aracı kazalarında, arama - kurtarma ekiplerinde bulunan akustik alıcılar vasıtası ile ULB sinyalleri tespit edilir ve kayıt cihazlarının sualtındaki konumları hesaplanır. Bu sayede kayıt cihazlarına ve uçak enkazına ulaşılabilir, kazanın kök nedenlerini bulmak için araştırmalar yapılabilir. Son yıllarda yaşanan bazı uçak kazalarında okyanusa düşen uçakların arama çalışmalarında ULB cihazlarının tespit edilemediği görülmüştür. Havacılık dünyasında sık tartışılan bir konu haline gelen ULB regülasyonları ile ilgili otoriteler bazı değişiklikler yapmışlardır. Bu çalışmada, sualtı akustik doğasının karakteristik özelliklerinden kaynaklanan etkilerin dışında, ULB cihazlarından beklenen performansın alınamamasının olası nedenleri, otoriteler tarafından yapılan değişikliklerin muhtemel etkileri ve hali hazırda problemin devam etmesine neden olabilecek faktörler incelenmiştir.

Anahtar Kelimeler:ULB; Underwater Locator Beacon, FDR, CVR, Uçak Kazaları 


\title{
Reliability Study of ULB Devices Used in Aircrafts
}

\begin{abstract}
FDR (Flight Data Recorder) and CVR (Cockpit Voice Recorder) devices, which are known as black boxes by the public, are very important for aviation. ULB(Underwater Locator Beacon) is an underwater sound projector which is activated by water immersion and it is attached to FDR and CVR in aviation use. If an aircraft is submerged in water after an air accident, ULB signal can be detected by hydrophones held by SAR teams and then underwater locations of the recorder devices will be calculated. Thus, wreckage and recorders can be found and investigations can be carried out to find out root causes of the accident. ULB devices could not be detected during search operations of some accidents occurred over the ocean in recent years. Authorities have been making some changes to ULB regulations which become a matter of debate in aviation community very often. In this study, possible causes of the unexpected low performance of ULB devices besides the effects originated by natural characteristics of the underwater acoustic environment, potential improvements of changes made by authorities, and existing other factors which may contribute to the problem were examined.
\end{abstract}

Keywords:ULB; Underwater Locator Beacon, FDR, CVR, Aircraft Accidents

\section{Giriș}

Havayolu ulaşımı en güvenli ve en konforlu ulaşım türü olmakla beraber hava aracı kazaları genelde ölümcül olmaktadır. Yaşanan kazalardan sonra hataların kök neden analizini yapmak ve tekrarlanmaması için önlemler almak çok önemlidir. Havacılığın bugünlere gelmesinde bu prensibin payı büyüktür. Kaza sonrasında FDR ve CVR kayıt cihazlarının analiz edilmesi ile beraber uçak enkazı üzerinde yapılan incelemeler araştırmaların temelini oluşturur. Uçağın sular altında kaldığı kaza vakalarında kayıt cihazlarının ve enkazın bulunmasında ULB'lerin görevi çok önemlidir. ULB (Underwater Locator Beacon) ; su ile temas ettiğinde belirli bir frekansta akustik sinyal yayan bir sualtı ses vericisidir. ULB'ler havac1l1kta, kara kutu olarak bilinen FDR ve CVR kayıt cihazlarının üzerine monte edilmiş olarak kullanılırlar. Güç kaynağının yettiği sürece sinyal verirler ve enkaz yeri tespit çalışmalarına büyük katk1 sağlarlar.[1]

Son yıllarda, ULB'ler okyanus üzerinde düşen uçakların yer tespitinde beklenen performansı verememişlerdir. 1 Haziran 2009 tarihinde AF-447 sayıl1 Rio De Janeiro - Paris seferini yapan, Air France havayollarına ait Airbus 330 tipi uçağın, 228 yolcu ve mürettebatı ile Atlantik Okyanusuna düşmesinin ardından yapılan arama - kurtarma çalışmaları sonuçsuz kalmış, enkazın bulunması yaklaşık 2 yıl sürmüş ve bu çalışmalar 40 milyon dolara mal olmuştu. $\mathrm{Bu}$ olayın ardından ULB cihazlarının güvenilirliği tartışılmaya başlanmıştır.
Yapılan çalışmaların ardından havacılık otoriteleri ULB regülasyonlarında bazı değişiklikler yapmış, FDR ve CVR kayit cihazlarına takılı olarak kullanılan ve $37.5 \mathrm{KHz}$ frekansında çalışan ULB'lerin batarya ömürlerinin 30 günden 90 güne çıkarılmasına ve $8.8 \mathrm{KHz}$ frekansında çalışan ayrı bir ULB'nin de uçak gövdesine takılmasına karar vermişlerdir.

ULB'lerin uçaklarda kullanılması ilk olarak 1968 yılında tartışılmaya başlanmıştır. 1968 yılında Amerikan havacilık otoritesi FAA, Dukane Corporation adlı şirkete bir ULB tasarlatmış, sualtı ortamında kaza benzetimi yapılarak test etmiş ve sonuçlarını açıklayan bir rapor yayınlamıştır. Bu cihaz tasarım özellikleri ve kullanım şekli ile havacılık endüstrisinde kullanılan ULB'lere çok benzemektedir[2]. ULB cihazlarının FDR ve CVR cihazlarına takılması 1977 yılında zorunlu hale getirilmiştir.[3,4].

Literatürde ULB'lerin geliştirilmesiyle ilgili çeşitli çalışmalar mevcuttur fakat çalışma prensibi olarak çok fazla değişime uğramamışlardır. 1976 yılında yapılan bir tasarımda piezo seramik kristal ve entegre devre osilatör kullanılarak hem menzil arttırılmış hem de daha ucuz bataryaların kullanılabilmesine olanak sağlanmıştır. Yinede o zamanın teknolojisi çalışma süresini 36 saat ile sinırlamıştır[5].

Günümüze kadar yapılan diğer çalışmaların genelde optimizasyona yönelik olduğu görünmektedir. 1990 yılında yapılan bir çalışmada 
konvansiyonel ULB'lerin problemi olan; sinyal seviyesinin kısıtlı güç imkânları nedeniyle, gürültü seviyesinin altına düşerek tespit edilmesinin zorlaşması durumuna çözüm önerilmiştir. Bunu, darbe modülasyonlu sinyal yerine geniş spektrum kodlu, faz kaydırma modülasyonlu sinyal kullanarak yapmıştır. Bu sayede verici gücü düşük tutulmakta, sinyalin gürültü içine gömülmesine izin verilmektedir. Böylece batarya daha tasarruflu kullanılmıştır. Eşsiz geniş spektrum kodlu sinyal çok zayıf olsa bile alıcı tarafından tespit edilebilir [6].

2010 yılında yapılan başka bir tasarımda ise ULB, FDR üzerine monte edilmiş olan kapalı bir korunak içine alınmıştır. ULB bataryası sisteme bağlanarak sürekli şarjda tutulmuş ve şarj durumu izlenerek kayıt altına alınmıştır. Bu çalışmada olası bir kaza durumunda ULB'nin daha az hasar alması amaçlanmış ve bataryayı her zaman tam güçte tutmak istenmiştir[7].

2012 yılında yapılan diğer bir çalışmada, ULB 'nin büyük ve derin okyanuslarda verimli çalışabilmesi için; boyutlarının küçük, batarya ömrünün uzun ve tüm yönlü yayılım özelliğinin olması gerektiği belirlenmiştir. $\mathrm{Bu}$ ihtiyaçlara cevap veren bir tasarım yapmak için Helmholtz Prensibinden faydalanılmıştır. ULB 'nin gövde yapısı değiştirilerek, etrafına piezo elektrik transdüser gömülü olan ve içine su giriş çıkışı olan bir boşluk oluşturulmuştur. Akustik dalga bu sistemle üretilmesi sağlanmıştır[8].

2013 yılında, ULB 'nin içine entegre bir basınç sensörü yerleştirilerek optimizasyon çalışması yapılmıştır. $\mathrm{Bu}$ sensör ULB'nin bulunduğu lokasyonda su basıncını ölçerek derinlik kestirimi yapar. Buna göre güç ve darbe tekrar optimizasyonu yaparak bataryayı daha tasarruflu kullanmayı amaçlar. Bu sayede arama kurtarma çalışmaları için daha uzun bir zaman sağlar[9].

2015 yılında yapılan bir araştırmada ise daha karmaşık ve gelişmiş bir ULB tasarımı yapıldığı görülmektedir. $\mathrm{Bu}$ çalışmada ULB'ye bir INS (Inertial Referance System) sistem entegrasyonu yaklaşımı denenmiştir. INS sistemi üzerine takı11 olduğu aracın manevrasinı Newton'un hareket yasasına göre ölçer. INS hata payının ise kabul edilebilir limitler içinde olduğu tespit edilmiştir[10].
ULB bataryasını daha tasarruflu kullanmak adına yapılan çalışmalara bir yenisi 2016 yılında eklenmiştir. Bu çalışmada uçaktaki GPS bilgisi kullanılarak coğrafi konum bilgisine ulaşılır. Sistemde her konum için güneşin doğuş ve batış saatlerini güncel olarak tutan bir hesaplayıc1 bulunur. Uçağın mevcut konumundaki havanın aydınlanma ve kararma vakitleri ULB'nin çalıșmasını ve durmasını tetikleyen bir kontrolöre iletilir. $\mathrm{Bu}$ sayede ULB'nin arama kurtarma faaliyetlerinin yapılamadığı karanlık vakitlerde boş yere çalışması engellenmiş olur[11].

$\mathrm{Bu}$ çalışmada, sualtı akustik doğasının karakteristik özelliklerinden kaynaklanan etkilerin dışında, ULB cihazlarından beklenen performansın alınamamasının olası nedenleri, otoriteler tarafından yapılan değişikliklerin muhtemel etkileri ve hali hazırda problemin devam etmesine neden olabilecek faktörler incelenmiştir.

\section{Su Altı Bulucu Beacon}

Son yıllarda yaşanan bazı uçak kazalarında, enkazın ve kayıt cihazlarının bulunması oldukça uzun sürmüş, hatta bazıları halen bulunamamıştır. Uçak kazaları halk nezdinde çok dikkat çektiği için, medya aracıllğı ile uzun süreler gündemde kalmaktadır. Uçak enkazının ve kayıt cihazlarının bulunamaması, kaza araştırmalarının sonuca ulaşamamalarına sebep olmaktadır. Böyle durumlarda başta kazazede yakınları olmak üzere halkın soruları cevapsız kalmakta, endişeleri giderilememektedir. Ayrıca kazaların kök nedenlerini bulmak, benzer olayların tekrar yaşanmaması için alınacak tedbirlerin temel dayanak noktalarını oluşturduğu için çok önemlidir. Arama çalışmalarının uzamasının başka bir dezavantajı da okyanus gibi derin sularda yapılan arama kurtarma operasyonlarının maliyetlerinin çok yüksek olmasıdır.

Neticede mevcut ULB ve sualtı yer belirleme teknolojilerinin bazı durumlarda yetersiz kaldığ 1 görülmüştür. Değişken ses hızı profili, yansıma, kırılma, saçılma, sinyal zayıflaması, özel yayılım kanalları, gürültü ve doppler etkisi gibiakustik haberleşme için sualtı ortamının doğasından kaynaklanan zorluklar da düşünüldüğünde, teknolojik ve sistemsel işleyişler bakımından 
araştırma ve geliştirmeye ihtiyaç duyulduğu anlaşılmaktadır.

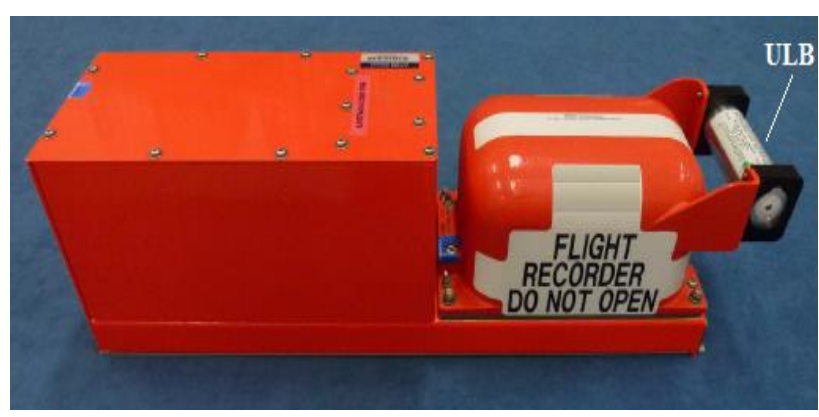

Şekil 1. FDR ve ULB

Okyanus üzerinde uçuş yapan bir uçak düştügünde, yapısal olarak yekpare kalmaması durumunda batmaya başlar. GPS, radar ve uçuş planı bilgileri uçağın son konumu hakkında tahminde bulunmaya yardımcı olabilir. Fakat bu tahminin nokta atışı olması pek olası değildir. Ayrıca uçağın son konumu \%100 doğru hesaplansa bile, bu bilgi batık enkazın bulunduğu derinliği göstermez. $\mathrm{Bu}$ durum, özellikle derin okyanus sularında arama kurtarma çalışmalarını oldukça zorlaștırır. Bazı kazalarda su üzerinde enkaz parçalarının ve yakıt kalıntılarının görüldüğü olmuştur. Fakat bunlar da enkazın konumu hakkında kesin bilgi vermez çünkü birçok vakada enkaz sualtında sürüklenerek çarpışma noktasından uzaklaşmıştır. Karada düşen uçaklarda, enkazın yerini tespit etmeye yardımcı olarak kullanılan ELT (Emergency Locator Transmitter) sistemi mevcuttur. $\mathrm{Bu}$ sistem darbe etkisi veya su temas 1 ile aktive olur ve acil durum merkezlerine 3 farklı frekansta elektromanyetik sinyal gönderir. Eğer uçak suya düştü ise, enkaz su üstünde yüzer halde iken, ELT sistemi aktive olursa görevini yapacaktır. Fakat enkaz suya battığında, elektromanyetik dalgalar suda çok hızlı emildiği için ELT sistemi faydasız hale gelir. Bu durumda özel bir sualtı yer tespit cihazına ihtiyaç vardır ve ULB bunun için tasarlanmıştır[12].

ULB sinyal yaymaya başladığı zaman, uçağın bilenen en son pozisyon tahminine göre konumlanmış olan arama kurtarma ekipleri, hidrofonlar vasitası ile ULB' den gelen sinyallerin gücünü ve geliş açısını bularak konumunu tespit etmeye çalışırlar. $\mathrm{Bu}$ hidrofonlar yönlü (directional) veya yönsüz (omnidirectional) olabilirler. Dalgıç, gemi, denizaltı, ROV ve AUV gibi çeşitli sualtı araştırma araçları ile kullanıma uygun hidrofon sistemleri mevcuttur.

Ticari hava taşımacılığı yapan uçaklarda kullanılan ULB cihazları piyasada birkaç farklı firma tarafinda üretilirler. Neredeyse tamamen aynı olan bu cihazlar, alüminyum kasa, batarya, elektronik devre, transdüser ve aktivasyon switch'i parçalarından oluşurlar[13].

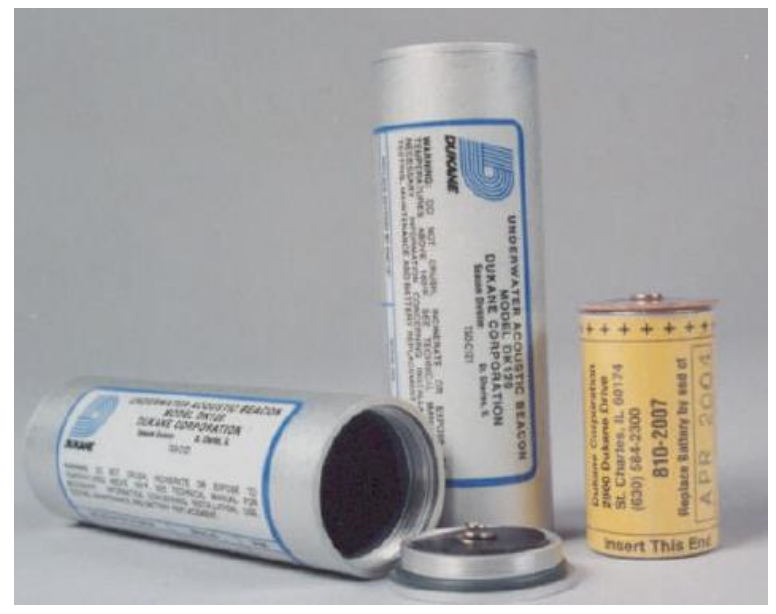

Şekil 2. Underwater Locator Beacon

Tablo 1.DK120/90 modelinin bazı özellikleri

\begin{tabular}{cc}
\hline Parametre & Değer \\
\hline Akustik çıkış (ilk) & $160.5 \mathrm{~dB}$ re $1 \mu \mathrm{Pa} @ 1 \mathrm{~m}$ \\
Akustik çıkış (son) & $157 \mathrm{~dB}$ re $1 \mu \mathrm{Pa} @ 1 \mathrm{~m}$ \\
Frekans & $37.5 \pm 1 \mathrm{KHz}$ \\
\hline Darbe süresi & Min. 9 milisaniye \\
\hline Darbe tekrar oranı & Min. 0.9 darbe/saniye \\
\hline Batarya çalışma ömrü & Min. 90 gün \\
\hline Batarya raf ömrü & 6 yıl \\
\hline Boyut & $3.3 \mathrm{~cm}$ çap, $9.95 \mathrm{~cm}$ boy \\
\hline Ağırlık & 190 gr \\
\hline
\end{tabular}

Günümüzde kullanılan ULB'ler, ilk örneklerinde olduğu gibi su ile aktive olduğu anda $37.5 \mathrm{KHz}$ frekansinda ultrasonik ses sinyalini ortama iletirler. ULB'ler literatürde zaman zaman "pinger" olarak da adlandırılırlar. Pinger'in aktivasyon switch'i, 
düşük akımlı tetikleme devresinin bir parçasıdır. $\mathrm{Bu}$ devre çalıştığında, osilatör devresi darbe sinyalini üretmeye başlar. Osilatör çıkış voltajının piezo-seramik transdüser halkasına uygulanmasıyla üretilen mekanik titreşim, alüminyum gövde vasıtası ile ortama iletilir.

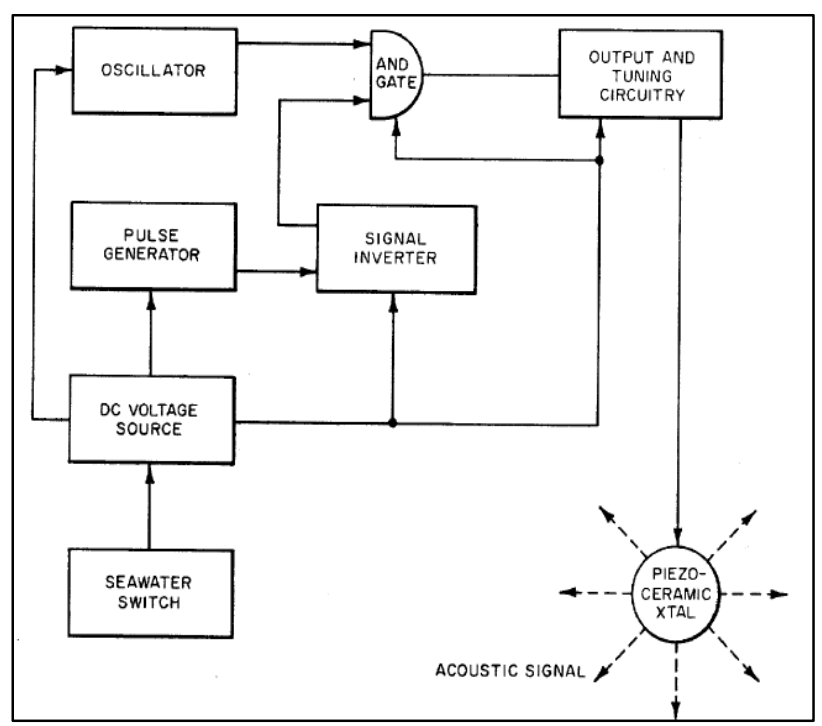

Şekil 3. ULB Blok Diyagramı[5]

\subsection{Uçak Üzerinde ULB Bakımı}

Uçak üreticilerinin, ULB standartlarına göre belirlenmiş, kullanımdaki ULB cihazları için bakım prosedürleri vardır. Uçak üzerinde yapılan bu işlemler, batarya değişimi ve sonrasında yapılan testler ve temizlik işlemleridir. ULB bataryasının ömrü, üreticisine göre değişmekle birlikte, genelde 6 ya da 7 y1l olarak belirtilir. Havayolu firmaları bu süreden önce batarya değişimini yapmak zorundadırlar. Bunun dişında, ulusal otoriteler tarafından mecbur kılınmış veya havayolu firmasının kendi inisiyatifi ile uyguladığ yoksa ULB'ler başka bir bakım işlemi görmezler[13].

ULB'lerin uçak üzerinde bulunduğu yerler, nem ve kir gibi yanlışlıkla aktivasyona sebep olabilecek etkenlere açıktır. ULB üreticileri, uçak üzerindeki kayıt cihazlarına takılı olan ULB'lerin, $6-7$ yılda bir yapılan zorunlu batarya değişimi ve testlerin dışında, her iki yılda bir temizlik ve test işlemine tabi tutulmasını tavsiye ederler. Amerikan Ulusal Taşımacılık Emniyet Kurulu NTSB, yaşanan kazaların ardından yaptığ 1 emniyet tavsiyelerinde, havayolu firmalarının, ULB üreticilerinin tavsiye ettiği bakım prosedürlerini uygulamadığını belirtmiş, batarya ve ULB'nin düzgün bir şekilde çalıştığından emin olmak için, periyodik testlerin planlı bir şekilde yapılması gerektiğini vurgulamıştır[13, 14].

\section{Uçak Kazası Vakaları}

\subsection{AF447}

1 Haziran 2009 tarihinde, Rio de Jenerio'dan Paris'e, 216 yolcu ve 12 mürettebatı ile AF447 numaralı uçuşu yapan, AirFrance şirketine ait Airbus 330-200 tipi yolcu uçağı Güney Atlantik Okyanusu üzerinde kayboldu. Uçağın bazı teknik problemler rapor ettikten kısa bir süre sonra düştüğ̈̈ anlaşıldı. Kazadan 16 gün sonra, su üzerinde yüzen birçok enkaz parçası bulundu. Uçağın enkazı ise, yaklaşık 2 yıl sonra, 2 Nisan 2011'de, 40 milyon dolar harcanarak yapilan arama çalışmalarının sonucunda bulunabilmiştir. Uçağın düşüş nedeni ise, hava hızını ölçen pitot tüplerinin buz kristalleri tarafından tıkanması nedeni ile uçağın yanlış hava hızı bilgisi algılaması ve takibinde uçuş ekibinin yaptığı yanlış müdahaleler sonucunda uçağın aerodinamik stall'a girmesi olarak açıklanmıştır. 10 Haziran - 10 Temmuz arasında yapılan ULB sinyallerini tespit etme çalışmaları sonuçsuz kalmıştır[12,15].

Kazadan 2 y1l sonra bulunan enkazın konumu göz önünde bulundurulduğunda, ULB sinyalini tespit etmek için toplamda $75 \mathrm{~km}$ çapında dairesel bir alanı tarayan detektörlerin, 22 ve 23 Haziran tarihlerinde, FDR ve CVR 'nin bulundukları bölgenin yakınından geçmesine rağmen, herhangi bir ULB sinyali tespit edilememiştir[16].

Kazadan sonraki arama kurtarma sürecinde, ULB'lerin çalışıp çalışmadığının bilinmesi imkânsızdır. Uçak enkazı bulunduktan sonra Fransiz havacılık otoritesi BAE, CVR'ye takılı olan ULB'yi incelemiş ve bazı testlere tabi tutmuştur. Yapılan ilk incelemelerde, ULB'nin iç kısımlarına su girmediği, elektronik devre ve piezoelektrik halkanın fiziksel olarak sağlam kaldığ 1 görülmüştür. Yapılan testlerde ise ULB'nin elektronik devresinin arızalı olması nedeniyle, akustik sinyal parametrelerinin olması gereken değerlerden çok uzak olduğu anlaşılmıştır[17]. 


\subsection{MH370}

8 Mart 2014 tarihinde, Kuala Lumpur'dan Beijing 'e, 227 yolcu ve 12 mürettebatı ile, MH370 sefer sayılı uçuşu yapan, Malezya Hava Yollarına ait, Boeing 777-200ER tipi yolcu uçağı Güney Çin Denizi üzerinde kayboldu. Havacılık tarihindeki en kapsamlı ve en maliyetli arama çalışmaları yapılmış olmasına rağmen, kayıp uçak halen bulunamamıştır. Uçağın neden kaybolduğu bilinmemekle birlikte, uçuşun ilk 38 dakikasından sonra uçakla iletişimin kesildiği, fakat radar ve uydu bilgilerinin analizine göre, uçağın 7 saat daha uçtuğu bilinmektedir. 1046 gün süren arama çalışmalarına 17 Ocak 2017 tarihinde son verildiği, Avustralya ulaştırma emniyet otoritesi ATSB tarafindan duyurulmuştur. $\mathrm{Bu}$ arama çalışmaları boyunca, deniz tabanında 710,000 $\mathrm{km}^{2}$ alan taranmış ve bunun için yaklaşık 200 milyon dolar harcanmıştır[18].

2 - 17 Nisan arasında yapılan ULB sinyalini tespit etme çalışmaları sonuçsuz kalmıştır. ULB üreticisinin, ULB'nin tahmini maksimum çalışma süresinin 40 gün olduğunu bildirmesi üzerine arama çalışmalarına son verilmiştir. $\mathrm{Bu}$ çalışmalarda birçok farklı sonar sistemi kullanılmıştır. 4 Nisan günü Haixun 01 isimli Çin 'e ait arama gemisi, 15 dakika boyunca, $37.5 \mathrm{KHz}$ frekansinda, saniyede bir tekrarlayan sinyal aldığını rapor etmiştir. Bir sonraki günde aynı bölgede aynı sinyali 90 saniye boyunca, daha zayıf bir şekilde tespit ettiğini bildirmiştir. Fakat bölgedeki okyanus derinliğinin 4500 metre olması, arama gemisinin tespit derinliğinin 2000 metre civarında olması, ayrıca bölgedeki diğer sonarların ve denizaltı araçlarının hiçbirinin bu sinyalleri algılayamaması nedeniyle, Haixun 01 gemisinin aldığ sinyallerin MH370'in ULB sinyalleri olmadığı şeklinde değerlendirme yapılmıştır. Ocean Shield isimli Amerikan arama gemisi ise, 5 - 10 Nisan tarihleri arasında, frekansları 32-43 $\mathrm{KHz}$ aralığında değişen sinyaller algıladığını bildirmiştir. Fakat yapılan analizlerden sonra bu sinyallerin ULB sinyal standartlarına uygun olmadığı anlaşılmıştır. Daha sonra, sonar teçhizatında arızalı bir test kablosu tespit edilmiş, bu kablonun, test için kullanılan ULB'yi aktive etmiş olabileceği, aynı zamanda $37.5 \mathrm{KHz}$ 'lik frekansta kaymalara sebep olabileceği açıklanmıştır. Ocean Shield gemisinin aldığ 1 sinyallerin arıza sonucu ortaya çıan yanıltıcı sinyaller olduğu şeklinde değerlendirme yapılmış olsa da, bazı uzmanlar, MH370'e ait ULB'lerin kazanın etkisiyle hasarlanıp arızalanmış olabileceği ve bu arızanın da frekans kaymalarına sebep olabileceği şeklinde yorum yapmışlardır[18].

\subsection{US1549}

15 Şubat 2009 tarihinde, US Airways şirketine ait, 1549 sefer sayıl1 Newyork City - Charlotte seferini yapan Airbus 320-214 tipi yolcu uçağ kalkıştan 2 dakika sonra Hudson nehrine acil iniş yaparak kırıma uğramıştır. Kazanın nedeni ise uçağın kuş sürüsüne girmesinin ardından motorlarının çalışmayı durdurması olarak açıklanmıştır. Kazanın ardından yolcular ve ekip uçaktan tahliye edilmiştir. Uçağın kayıt cihazları Amerikan Ulusal Taşımacılık Emniyet Kurulu NTSB tarafından incelemeye alınmıştır. $\mathrm{Bu}$ inceleme raporlarında, CVR üzerindeki ULB ile ilgili bazı bulgular vardır. ULB bataryasının son kullanma tarihi Ekim 2009 olmasına rağmen, yapılan testlerde ULB'nin çalışmadığı, batarya zayıf ikazı alındığı görülmüştür[19].

\subsection{Air India Flight 182}

23 Haziran 1985 'de, 182 numaralı TorontoDelhi seferini yapan, Air India firmasina ait, 307 yolcu ve 22 mürettebat taşıan, Boeing 747 tipi yolcu uçağ 1 , bombalı suikast sonucu havada parçalanarak Atlantik Okyanusuna düşmüştür. Enkazın bulunduğu bölgenin belirlenmesinin ardından, FDR ve CVR cihazlarını bulmak için 3 gemi görevlendirilmiştir. Bu bölgedeki su derinliği yaklaşık 2000 metre, deniz tabanı ise düzdür. Kazadan 11 gün sonra arama gemilerinden biri, frekansları $39-42 \mathrm{KHz}$ aralığında değişen iki farklı ses sinyali aldığını belirtmiştir. ULB üreticisinden alınan tavsiye ile ULB transdüserinin almış olabileceği hasardan dolayı, olması gerekenden daha yüksek frekanslarda sinyal üretebileceği, fakat darbe tekrar oranının değişmeyeceği anlaşılmıștır ve sonar frekansının üst limiti 45 KHz'e yükseltilmiştir. Kazanın 17. günü CVR, 18. günü de FDR bulunmuştur[20].

Yaklaşık 9500 metre irtifada uçarken, bomba patlaması sonucu okyanusa düşen uçakta ULB 
cihazları sağlam kalmıştır. Okyanus şartlarının da elverişli olması ile birlikte FDR ve CVR konumları ULB sinyalleri sayesinde tespit edilmiştir.

\subsection{MS804}

19 Mayıs 2016 tarihinde, Misır havayollarına ait, MS804 numaralı Paris - Kahire seferini yapan, 56 yolcu, 7 mürettebat ve 3 güvenlik görevlisi olmak üzere 66 kişi taşıyan Airbus 320 tipi uçak Akdeniz'de düşmüştür. Uçak, çeşitli bölgelerinde duman olduğuna dair ikaz verdikten kısa bir süre sonra radardan kaybolmuştur. Uçağın düştügü bölgede su derinliği yaklaşık 3000 metredir. Enkazın su altındaki konumu 15 Haziranda tespit edilebilmiştir. 16 Haziranda CVR, 17 Haziranda ise FDR bulunmuştur. Deep Ocean Search adlı şirkete ait olan gemiden, 3000 metre derinliğe indirilen ROV, ULB'lerden gelen sinyali tespit edip, yön ve mesafe hesabı ile konum belirlemesi yapmıştır. Kaza raporları henüz açıklanmadığından uçağın kesin düşüş nedeni bilinmemektedir. ULB sinyallerinin, batarya gücünün bitmesine birkaç gün kala tespit edilebildiği gözden kaçırılmamalıdır[21,22].

\section{Derleme}

1980 - 2010 yılları arasında, derin sulara düşen ve araştırmaları BAE tarafından yapılan 27 uçak kazası vardır. Bu kazalarda kayıt cihazları üzerinde bulunan 52 ULB'den 5 tanesinin çalışmadığg ifade edilmiştir. Bu kazalara AF447, MH370, US1549 kazaları ve bazı diğer kazalar dâhil değildir. Ortalama olarak yılda bir kez derin sulara düşmeyle sonuçlanan uçak kazası yaşanmaktadır[15].

Derin sularda düşen uçakların ULB arama çalışmalarının başlangıcında dahi, gecikmelere neden olabilecek birçok faktör vardır. Bunlar; son pozisyon bilgisinin doğruluk derecesi, kaza bölgesinin uzaklığı, kazadan kurtulan olma ihtimali ile arama kurtarma çalışmalarına önce bu yönde ağırlık verilmesi, ULB arama ekipmanları ve personellerin gölgeye ulaştırılması ve hava durumu gibi etkenlerdir. ULB arama çalışmalarında ortalama olarak günlük $100 \quad \mathrm{~km}^{2}$ 'lik alan taranmaktadır. $\mathrm{Bu}$ çalışmalara 7. günden sonra başlanıldığ 1 varsayılırsa, 30 günlük süre içersinde $2300 \mathrm{~km}^{2}$ 'lik bir alan taranabilir. Bu yüzden son pozisyon bilgisi çok önemlidir. $37.5 \mathrm{KHz}$ frekansında çalışan ULB cihazlarının tespit edilme mesafesi, deniz durumu ve ses hizı profili gibi faktörlerin etkisiyle değișmekle birlikte $2-3 \mathrm{~km}$ civarındadır. Yüzeyden arama yapan hidrofonlar, 2 $\mathrm{km}$ derinliğe kadar verimli çalışabilirler. Bundan daha derin sularda ise, suya daldırılan sonar teçhizatları gereklidir. Bu sonarlar ile ULB yerinin tam tespiti için birkaç farklı noktadan sinyal tespit çalışması yapılmalıdır. Bazı durumlarda ULB uçak enkazının altında kalabilir ve bu sinyalin yayılımını negatif etkiler. Diğer bir ihtimalde kaza olduğunda ULB cihazlarının çalışır durumda olmamalarıdır. AF447 kazasında bu iki ihtimal üzerinde durulmuştur[18].

Yapılan bir araştırmada ise, ULB sinyalinin darbe tekrar oranının çok kısa olduğu, bu sürenin uzatılmasıyla bataryanın daha tasarruflu kullanılabileceği belirtilmiştir. Diğer bir araştırmada ise ULB sinyalinin jamming'den etkilenebileceği, ayrıca bu sinyallerin kötü amaçlı kişiler tarafından da tespit edilebileceği ifade edilmiştir[6, 17].

Yaşanan kazalardan sonra otoriteler, ULB bataryalarının ömrünü 30 günden 90 güne çıkarmıştır. Ayrıca düşük frekansta $(8.8 \mathrm{KHz})$ çalışan ULD cihazlarının da uçakların gövdesine takılması kararlaştırılmıştır. Böylece ULB cihazlarının arama çalışmaları daha kapsamlı ve etkili bir şekilde yapılabilecektir. Düşük frekanslı ULD sayesinde, tespit mesafesi yaklaşık 10 - 12 kilometreye kadar arttırılmış, cihaz uçak enkazının altında kalsa bile sinyalinin zayıflama ihtimali azaltılmış ve arama çalışmalarına düşük frekanslı sonar teçhizatına sahip birçok aracın da katılabilmesine olanak sağlanmıştır. ULD'lerin darbe tekrar süresi uzun tutularak, bataryayı daha verimli kullanmaları sağlanmıştır.

Uçaktaki acil durum ekipmanları her uçuş öncesi kontrol edilir. Uçakların günlük bakımlarında da bu kontroller yapılır. ULB, acil durum ekipmanı olarak değerlendirilmese bile, zorunlu bakım periyodunun, benzer sistemlerin bakım periyodundan çok daha uzun olması dikkat çekicidir. Örneğin ELT sistemleri, ULB 'nin su altında yaptığı işin benzerini karada ve su üzerinde yaparlar. Uçakta sabit ve taşınabilir olmak üzere iki çeşit ELT sistemi bulunabilir. Sabit ELT sistemlerinin çalışma testleri yılda bir, taşınabilir 
ELT sistemlerinin çalışma testleri ise 6 ayda bir yapılır. ELT sistemleri, ULB'ye benzer şekilde, tek kullanımlık batarya ile çalışır. Ayrıca ELT ekipmanlarının üzerlerinde, kendi test düzenekleri vardır ve bu şekilde çok hızlı ve basit bir şekilde testleri yapılabilir. ULB cihazlarında böyle bir donanım yoktur ve test edilmeleri için harici bir cihaz kullanılmaktadır.

\section{Sonuçlar}

Otoritelerin ULB minimum batarya ömrünü 30 günden 90 güne çıkarması ve $8.8 \mathrm{KHz}$ frekansında çalışan yeni ULB cihazlarını kullanıma sokması sayesinde, ULB tespit çalışmalarındaki iki ana problem olan kısa menzil ve zaman kisitlamasina çözüm bulunmuştur.

Yaşanan uçak kazalarına bakılacak olursa, su üzerine yumuşak iniş yapan bir uçaktaki ULB'lerden birinin çalışmadığı görüldüğü gibi, bomba patlaması sonucu denize çakılan bir uçaktaki her iki ULB'nin de sağlam kaldığı ve çalıştığı görülmüştür. Ayrıca AirFrance kazasında, ULB arama ekipmanları, ULB'lerin çok yakınından geçmiş olmasına rağmen sinyali tespit edememiştir ve daha sonra yapılan incelemelerde CVR'ye takılı olan ULB'nin arızalı olduğu anlaşılmıştır. Neticede, bazı ULB'lerin kazalar yaşanmadan önce bozulmuş olma ihtimallerinin olması, ULB bakım periyotlarının çok uzun olması, benzer sistemlerde olduğu gibi kolayca test yapmaya imkan veren dahili test düzeneklerinin olmaması, ULB bakımına verilen önemin ve bakım uygulamalarının revizyona ihtiyaç duyduğunun önemli göstergeleridir. Sonuç olarak, ULB cihazlarının uçak üzerindeki bakım faaliyetlerinin daha kapsamlı ve sık bir şekilde yapılmasının bazı riskleri ortadan kaldırmak için faydalı olabileceği anlaşılmaktadır.

Hiç çalışmayan veya istenen performansta çalışmayan ULB'lerin tespiti için uçak üzerindeki bakım faaliyetlerinde olağanın dışında bir uygulama henüz yapılmamaktadır. $\mathrm{Bu}$ bakım faaliyetlerinin kapsamının ve sıklığının arttırılması, yaklaşık olarak yılda bir kez deniz ve okyanus bölgelerinde uçak kazası yaşandığı düşünüldüğünde, kaçınılmaz bir gerekliliktir. ULB cihazlarına dâhili test tertibatının yerleştirilmesi, akustik radyasyon paterninin bozulması ihtimalini doğurabilir ve kullanımdaki ULB cihazlarının tümünü değiştirmek zaten maliyet açısından pek uygulanabilir değildir. Daha pratik ve verimli bir bakım için, bakım personelinin rahatça ulaşabileceği, kullanımı kolay ve fazla ağırlık yükü getirmeyen, batarya voltaj1, frekans, genlik, akustik basınç seviyesi, darbe süresi ve hatalı aktivasyon gibi önemli parametrelerin takibini yapabilen, harici bir test ve izleme donanımının uçağa takılması uygun bir çözüm olabilir.

\section{Kaynaklar}

[1] http://www.ntsb.gov/safety/safetyrecs/recletters/a-15-001-008.pdf. [Erişim Tarihi: 17-Şubat-2016].

[2] http://www.fire.tc.faa.gov/pdf/na68-7.pdf. [Erişim Tarihi: 20-Ekim-2016].

[3] http://rgl.faa.gov/Regulatory_and_Guidance _Library/rgFAR.nsf/0/95BF75814BC85D3 A85256673004EF515?OpenDocument. [Erişim Tarihi: 20-Ekim-2016].

[4] http://rgl.faa.gov/Regulatory_and_Guidance _Library/rgFAR.nsf/0/6875BE9FA3130F2B 85256673004EF5DE?OpenDocument.

[Erişim Tarihi: 20-Ekim-2016].

[5] Armand Jay Filer, Programmable Underwater Acoustic Beacon, 1976, 3,992,692., United States Patent

[6] Steven M. Shope, Spread Spectrum Underwater Location Beacon System, 1990, 4,951,263., United States Patent

[7] Michael C. Winterhalter, Endre Berecz, Locator Beacon Disposed Internal to an Enclosure of a Flight Data Recorder and Method Therefor, 2010, US 20100063654A1, United States Patent

[8] Walden, Tim Steller, A Transducer for a Locator Beacon and an Underwater Locator Beacon, 2012, EP2735380A1, EUROPEAN PATENT

[9] Jianhua Zheng, A New Design of Underwater Locator Beacon with Integrated Pressure Sensor, 2013, 2013088275 A1, World Intellectual Property Organization (WIPO)

[10] S. S. Wang, H. S. Hung, J. J. Ho, J. X. Ling, C. H. Yeh, “ Improving Detection 
Technique for Flight Recorders of the Distress Airplanes Crashed into Ocean by Integrating Inertial Navigation System into Underwater Locator Beacon,"Journal of Marine Science and Technology,23(4), 467474, 2015.

[11] H. Jay Spiegel, Extended Life, Timed Pinger for Aircraft, 2016, US9268310 B2, United States Patent

[12] https://fenix.tecnico.ulisboa.pt/downloadFile 1395143172650/dissertacao.pdf. [Erişim Tarihi: 12-Haziran-2014].

[13] http://www.radiantpowercorp.com/wpcontent/uploads/2015/04/DK120-90-TechManual-03-TM-0063-REV-A.pdf. [Erişim Tarihi: 30-Ocak-2018].

[14] https://www.casa.gov.au/file/151971/downlo ad?token=bk9o7Ylr. [Erişim Tarihi: 17Ocak-2018].

[15] https://www.bea.aero/uploads/tx_elyextendtt news/metron.search.analysis.pdf. [Erişim Tarihi: 23-Ağustos-2016].

[16] https://www.bea.aero/docspa/2009/fcp090601.en/pdf/f-cp090601.en.pdf. [Erişim Tarihi: 18-Ocak-2018].

[17] D. J. Eckman, L. M. Maillart, A. J. Schaefer, "Optimal Pinging Frequencies in the Search for an Immobile Beacon,"IIE Transactions, 48(6), 489-500, 2016.

[18] https://www.atsb.gov.au/media/5773565/ope rational-search-formh370 final 3oct2017.pdf. [Erişim Tarihi: 18-Ocak-2018].

[19] http://graphics8.nytimes.com/packages/imag es/nytint/docs/documents-for-the-testimonyof-us-airways-flight-1549/original.pdf. [Erişim Tarihi: 22-Ocak-2018].

[20] https://ia800309.us.archive.org/23/items/Rep ortOfTheCourtInvestigatingAccidentToAirI ndia747On23rdJune1985/ReportOfTheCourt InvestigatingAccidentToAirIndia747On23rd June1985.pdf. [Erişim Tarihi: 18-Ocak2018].

[21] http://avherald.com/h?article=4987fb09.

[Erişim Tarihi: 21-Şubat-2018].
[22] http://www.deepoceansearch.com/newwebsi te/2016/09/09/natoque-penatibus-etiammagnis-dis-parturient/. [Erişim Tarihi: 21Şubat-2018]. 